\title{
Bladder Neck Obstruction in Women
}

\author{
Ananias C. Diokno \\ Department of Urology, William Beaumont Hospital, Royal Oak, Michigan and Department \\ of Surgery-Urology, University of Michigan Medical School, Ann Arbor

\begin{abstract}
Bladder neck obstruction in women is uncommon. It should be suspected in patients with chronic symptoms of obstruction and irritation, and with signs including bladder trabeculation, diverticula, and vesicoureteric reflux. Accurate diagnosis can be established using the simultaneous pressure-flow fluoroscopy study. A specific surgical approach to correct
\end{abstract} \\ the bladder neck obstruction may be justified with proper urodynamic documentation.
}

Key words: outlet obstruction, urodynamic diagnosis, female retention

Marion in 1933 described what is probably the first characterization of primary bladder neck obstruction. He reported "dysuric disturbances similar to those giving rise to hypertrophy of the prostate, disturbances caused by alterations of the bladder neck without any visible lesions of the neck and which cannot be attributed to nerve injuries." The existence of this entity in men is unquestioned. In women, its existence is questioned. In 1975, Farrar and associates reported observing four cases (2\%) among 169 female patients complaining of voiding difficulties [Farrar et al, 1975]. In 1984, we reported our experience of three cases seen at Michigan with urodynamic documentation [Diokno et al, 1984]. In this presentation I would like to summarize the clinical presentations and urodynamic findings of those women with bladder neck obstruction.

The voiding history of these women is bizarre and does not fit any one known bladder dysfunction category. Irritable bladder symptoms of urinary frequency, urgency, and nocturia are consistent. They have consistently received anticholinergic, and antispasmodics for a suspected diagnosis of hyperactive bladder. Another consistent symptom is suprapubic pain either during or after voiding. The women usually end up having periodic urinary retention or are discovered on a random check to have elevated residual urine. Finally, recurrent urinary tract infection of the cystitis variety is very frequent.

Received for publication September 30, 1985; accepted January 20, 1986.

Address reprint requests to Dr. A.C. Diokno, Department of Urology, William Beaumont Hospital, 3601 W. 13 Mile Rd., Royal Oak, MI 48072.

(C) 1986 Alan R. Liss, Inc. 
The initial urologic evaluation should include a cystogram or, if possible, a voiding cystourethrogram. Generally, a cystogram is evaluated at the time of excretory pyelography. The cystogram usually shows trabeculations, diverticulum formation, or vesicoureteric reflux.

An initial urine flow study will confirm a poor flow or no flow at all (if in retention). A cystometrogram will show normal or large bladder capacity with a negative urecholine supersensitivity test.

Cystourethroscopy has been unreliable in detecting primary bladder neck obstruction. In our cases, one patient was described as having a "tight bladder neck." Certainly, bladder wall changes may be observed.

Pressure flow study with simultaneous voiding cystourethrography will clinch the diagnosis. The criteria for diagnosis of bladder neck obstruction in females should include normal or elevated detrusor voiding pressure. The external sphincter should relax, as evidenced either by sphincter electromyography or reduction of urethral pressure during voiding. The urine flow rate is poor and the bladder neck does not funnel during voiding. With these strict criteria, unnecessary operations at the bladder neck can be avoided. The procedure to correct this problem is either by suprapubic bladder neck plasty or transuretheral incision of the bladder neck.

\section{REFERENCES}

Marion G (1933): Surgery of the neck of the bladder. Br J Urol 5:351.

Farrar JJ, Osborne JL, Stephenson TP, Whiteside CG, Weir J, Berry J, Milroy EJG, Turner Warwick R (1975): A urodynamic view of bladder outflow obstruction in the female: Factors influencing the results of treatment. Br J Urol 47:815.

Diokno AC, Hollander JB, Bennett CJ (1984): Bladder neck obstruction in women: A real entity. J Urol 132:294. 